\title{
EFFECT OF CALCIUM AND CHOLECALCIFEROL SUPPLEMEN- TATION ON SEVERAL PARAMETERS OF CALCIUM STATUS IN PLASMA AND URINE OF CAPTIVE ASIAN (ELEPHAS MAXIMUS) AND AFRICAN ELEPHANTS (LOXODONTA AFRICANA)
}

\author{
Gerda R. van Sonsbeek, D.V.M., Johannes H. van der Kolk, D.V.M., Ph.D., Dipl. E.C.E.I.M., Johannes \\ P. T. M. van Leeuwen, Ph.D., Hendrik Everts, D.V.M., Ph.D., Johan Marais, B.V.Sc., M.Sc., and \\ Willem Schaftenaar, D.V.M.
}

\begin{abstract}
The aim of the current study was to assess the effect of oral calcium and cholecalciferol supplementation on several parameters of calcium status in plasma and urine of captive Asian (Elephas maximus; $n=10$ ) and African elephants (Loxodonta africana; $n=6$ ) and to detect potential species differences. Calcium and cholecalciferol supplementation were investigated in a feeding trial using a crossover design consisting of five periods of 28 days each in summer. From days 28-56 (period 2), elephants were fed the Ca-supplemented diet and from days 84-112, elephants were fed the cholecalciferol-supplemented diet (period 4). The control diet was fed during the other periods and was based on their regular ration, and the study was repeated similarly during winter. Periods 1, 3, and 5 were regarded as washout periods. This study revealed species-specific differences with reference to calcium and cholecalciferol supplementation. Asian elephants showed a significant increase in mean plasma total calcium concentration following calcium supplementation during summer, suggesting summerassociated subclinical hypocalcemia in Western Europe. During winter, no effect was seen after oral calcium supplementation, but a significant increase was seen both in mean plasma, total, and ionized calcium concentrations after cholecalciferol supplementation in Asian elephants. In contrast, evidence of subclinical hypocalcemia could be demonstrated neither in summer nor in winter in African elephants, although 28 days of cholecalciferol supplementation during winter reversed the decrease in plasma $1,25(\mathrm{OH})_{2}$-cholecalciferol and was followed by a significant increase in mean plasma total calcium concentration. Preliminary findings indicate that the advisable permanent daily intake for calcium in Asian elephants and cholecalciferol in both elephant species at least during winter might be higher than current guidelines. It is strongly recommended to monitor blood calcium concentrations and, if available, blood parathyroid hormone levels to adjust the nutritional supplementation for each individual elephant.
\end{abstract}

Key words: African elephant, Asian elephant, calcium, cholecalciferol, Elephas maximus, Loxodonta africana.

\section{INTRODUCTION}

Hypocalcemia may cause problems in captive Asian elephants (Elephas maximus), particularly during parturition. ${ }^{17,20}$ The disorder is associated with dystocia in other species, and there are some indications that this may also play a role in captive

From the Faculty of Veterinary Medicine, Department of Equine Sciences, Medicine Section, University of Utrecht, Postbus 80163, 3508TD Utrecht, The Netherlands (van Sonsbeek, van der Kolk); the Erasmus University Medical Center, Department of Internal Medicine, Postbus 2040, 3000CA Rotterdam, The Netherlands (van Leeuwen); the Department of Farm Animal Health, Faculty of Veterinary Medicine, University of Utrecht, Postbus 80151, 3508TD Utrecht, The Netherlands (Everts); the University of Pretoria, Department of Equine Sciences, 0110 Pretoria, South Africa (Marais); and Rotterdam Zoo, Postbus 530, 3000AM Rotterdam, The Netherlands (Schaftenaar). Present address (van Sonsbeek): Diergeneeskundig Centrum Maas \& Waal, Klepperheide 16, 6651KM Druten, The Netherlands. Correspondence should be directed to Dr. van Sonsbeek (lindavansonsbeek4@hotmail.com). elephants. ${ }^{1720,39}$ According to the European Asian Elephant Studbook, 35 out of 144 elephants calves were stillborn since 1980 . That would amount to $24 \%$ of all Asian elephant calves born in captivity in European zoos. ${ }^{2,17}$

Although several studies have described the blood mineral status in predominantly Asian elephants, ${ }^{1,4-6,9,11,14,20,22,25-27,34-36,38,40}$ only a few studies have addressed calcium status in elephants. ${ }^{20,25}$ To the authors' knowledge, only one study involved assessment of markers of bone status in Asian elephants. ${ }^{18}$ In elephant hospitals in Thailand, bone fractures are regularly seen in semicaptive Asian elephants. ${ }^{23,30}$ In Lampang Veterinary Hospital, for example, bone fractures and lameness comprised 13 and $8.3 \%$ of elephant admissions, respectively, from January 2005 through July 2007. ${ }^{23}$ Similar data were provided by Kasetsart Veterinary Hospital from 1997 through 2007, revealing $18 \%$ of the elephants being admitted for musculoskeletal or locomotion problems. Besides fractures and lameness, socalled trunk weakness has also been reported. ${ }^{30}$ 
Symptoms of trunk weakness not only include a weak trunk but also whole body shivering. Unfortunately, no blood calcium concentrations had been measured in these cases. Furthermore, rickets in hand-reared elephant calves, as confirmed by autopsy, was also mentioned and associated with deficient nutrition. ${ }^{30}$ Unpublished data report the incidental collapse of free-ranging African elephants (Loxodonta africana) attributed to potential hypocalcemia after prolonged confinement in a livestock pen during the process of translocation in South Africa (Dr. Kobus du Toit, wildlife veterinarian, South Africa, pers. comm.).

The aim of the current study was to assess the effect of oral calcium and cholecalciferol supplementation in a feeding trial on different plasma and urine parameters of calcium status in captive Asian and African elephants and to detect potential species-specific differences. It was hypothesized that these treatments were effective in normalizing plasma (ionized) calcium concentration in case of potential hypocalcemia and thereby preventing (sub)clinical hypocalcemia. Subclinical hypocalcemia is defined as the condition in which the plasma-ionized calcium concentration can be enhanced by oral supplementation of calcium and/or cholecalciferol. Apart from testing mineral concentrations and vitamin D metabolites in plasma and urine, bone alkaline phosphatase (BAP), which is a marker for bone production, and nitrogen terminal telopeptide of type I collagen $\left(\mathrm{NT}_{\mathrm{x}}\right)$, which is a marker for bone resorption, were also measured.

\section{MATERIALS AND METHODS}

\section{Animals and diets}

Ten Asian and six African female elephants from four different zoos (Hannover Zoo, Germany; Antwerp Zoo, Belgium; Safaripark Beekse Bergen, The Netherlands, and Rhenen Zoo, The Netherlands) participated in a feeding trial. The age of the Asian elephants ranged from 5-47 yr (mean $24.7 \pm$ $12.9 \mathrm{yr}$ ), and their body weight (BW) ranged from $1,400-4,444 \mathrm{~kg}$ (mean $3,028 \pm 860 \mathrm{~kg}$ ). The age of the African elephants ranged from 11-37 yr (mean $22.2 \pm 7.6 \mathrm{yr}$ ) and their BW ranged from 3,000$3,500 \mathrm{~kg}$ (mean $3,167 \pm 236 \mathrm{~kg}$; Table 1).

In a crossover design, the study consisted of five periods of 28 days each in summer. From days 28-56 (period 2), elephants were fed the $\mathrm{Ca}$ supplemented diet and from days 84-112 elephants were fed the cholecalciferol-supplemented diet (period 4). The control diet was fed during the other periods and was based on their regular
Table 1. Elephant species, zoo location, body weight, and ages of animals.

\begin{tabular}{llcc}
\hline $\begin{array}{c}\text { Zoo and } \\
\text { elephant No. }\end{array}$ & Species & $\begin{array}{c}\text { Year of } \\
\text { birth }\end{array}$ & $\begin{array}{c}\text { Body } \\
\text { weight }(\mathrm{kg})\end{array}$ \\
\hline Safaripark & & & \\
1 & L. africana & 1986 & 3,500 \\
2 & L. africana & 1987 & 3,000 \\
3 & L. africana & 1987 & 3,500 \\
4 & L. africana & 1987 & 3,500 \\
Rhenen Zoo & L. africana & 1971 & 3,000 \\
5 & L. africana & 1997 & 3,000 \\
6 & E. maximus & 1973 & 3,100 \\
Hannover Zoo & E. maximus & 2003 & 2,000 \\
7 & E. maximus & 1961 & 3,600 \\
8 & E. maximus & 1981 & 3,200 \\
9 & E. maximus & 1982 & 2,300 \\
10 & E. maximus & 2003 & 1,400 \\
11 & E. maximus & 1996 & 3,500 \\
12 & & & \\
13 & E. maximus & 1974 & 4,444 \\
Antwerp Zoo & E. maximus & 1981 & 2,960 \\
14 & E. maximus & 1979 & 3,778 \\
15 & & &
\end{tabular}

a All elephants were female.

ration. The study was repeated during winter similarly. Given the setup of the study, each animal served as its own control. Urine and plasma samples were taken six times in both trials at the time points marking the various periods.

Periods 1, 3, and 5 were regarded as washout periods based on a previous study. ${ }^{20}$ The hypothesis was not focused on whole-body calcium deficiency but on the effects of calcium and cholecalciferol supplementations on mineral and hormone concentrations in plasma and urine.

The regular (control) diet consisted of grass hay fed ad libitum, and each ration was supplemented with a small amount of bread, fruit, and lettuce. The small amounts of bread, fruit, and lettuce were provided for training purposes to facilitate animal handling and sample collection. The food intake during calcium or cholecalciferol supplementation was also recorded. The relevant mineral composition of the roughage fed in each zoo (summer and winter separately) was assessed by a commercial laboratory (Provimi, Rotterdam, The Netherlands). Gravimetry was used to analyze dry matter (DM), whereas minerals were analyzed by inductively coupled plasma atomic emission spectroscopy. As cholecalciferol is a vitamin exclusively of animal origin, the plant-based diet was not analyzed for it. 
Oral calcium supplementation was provided using pellets containing $60 \mathrm{~g}$ of calcium and 0 IU cholecalciferol per kilogram DM administered as $1-\mathrm{kg}$ calcium rich pellets per $1,000 \mathrm{~kg}$ of $\mathrm{BW}$. Additional cholecalciferol was supplied using pellets containing 9,998 IU cholecalciferol $/ \mathrm{kg}$ pellet compared with 2,000 IU cholecalciferol/ $\mathrm{kg}$ regular pellet. By feeding 1-kg cholecalciferolrich pellets per $1,000 \mathrm{~kg}$ of $\mathrm{BW}$, it was aimed to increase the cholecalciferol supply with about 8 $\mathrm{IU} / \mathrm{kg}$ BW. This supplementation was based on the assumption that a calcium content in the DM of $0.3-0.7 \%$ is sufficient for elephants. ${ }^{10,41}$ Assuming that Asian elephants have a DM intake of approximately $1.5-1.9 \%$ of their BW and African elephants of $1.0-1.5 \%$, it can be calculated that a daily calcium intake based on a calcium content in the DM of $0.3-0.7 \%$ equals $45-133 \mathrm{mg} / \mathrm{kg} \mathrm{BW}$ and $30-105 \mathrm{mg} / \mathrm{kg} \mathrm{BW}$, respectively. ${ }^{41}$ A vitamin D intake of $800 \mathrm{IU} / \mathrm{kg}$ DM was also advised. ${ }^{41}$ However, it was not specified if cholecalciferol or a combination of cholecalciferol and ergocalciferol was needed. It was calculated based on the above suggestion, that the daily vitamin $\mathrm{D}$ intake would be 8-12 IU/kg BW and 12-15 IU for Asian and African elephants, respectively.

Furthermore, pellet production itself, on the other hand, limited the amount of calcium to be added to pellets due to the inability to produce firm enough pellets when their calcium content exceeds a maximum level. All zoos used both the calcium and cholecalciferol pellets from the same batch, whereas each zoo used its own roughage. The intake of calcium and phosphorus was calculated by multiplying the amount of food consumed by each elephant with the quantity (milligrams) of calcium and phosphorus per kilogram of food.

\section{Clinical biochemistry and endocrinology}

Blood was collected from the ear vein using heparinized syringes (Rapid Lite ${ }^{\circledR}$ 3-ml syringe, Bayer HealthCare, Leverkusen, 51368, Germany). After collection, the blood was centrifuged for 5 min at 17,609 $\mathrm{g}$, and plasma was separated from erythrocyte fractions. Heparinized venous plasma was stored at $-20^{\circ} \mathrm{C}$ and analyzed at the end of each seasonal trial. The plasma ionized calcium concentration was corrected at $\mathrm{pH} 7.4$ using the following equation:

$$
\begin{aligned}
\mathrm{iCa}_{7.4}= & -2.1075+0.3130 \mathrm{pH}_{\text {actual }} \\
& +0.8296 \mathrm{iCa}_{\text {actual }}
\end{aligned}
$$

to facilitate comparison between individual ele- phants as published previously. ${ }^{37}$ Plasma samples were analyzed for total calcium (0-Cresolphthalein Complexone, Spotchem SP-4410 autodry chemistry analyzer, Menarini Diagnostics BENELUX NV, Valkenswaard, 5555XK, The Netherlands); ionized calcium (silver/silver chloride electrode, Rapid Lab 850 Blood Gas analyzer, Siemens Medical Solutions, Breda, 4824 AT, The Netherlands ), pH (Ion Selective Electrode technology, silver/silver chloride inner conductor; Rapid Lab 850 Blood Gas analyzer, Siemens Medical Solutions); inorganic phosphorus (ammoniummolybdate tetrahydrate $\mathrm{L}(+)$-ascorbine, Spotchem SP4410 autodry chemistry analyzer, Menarini Diagnostics BENELUX NV); creatinine (3,5-dinitrobenzoic acid Spotchem SP-4410 autodry chemistry analyzer, Menarini Diagnostics BENELUX NV); BAP (Ostase ${ }^{\circledR}$ BAP kit, IDS Ltd., Boldon, NE35 9PD, United Kingdom), NTx (Osteomark ${ }^{\circledR} \mathrm{NT}_{\mathrm{x}}$ serum kit, Wampole Laboratories, Princeton, New Jersey 08540, USA); 25-hydroxycholecalciferol (LIAISON ${ }^{\circledR}$, DiaSorin Inc., Stillwater, Minnesota 55082, USA); and 1,25-dihydroxycholecalciferol (RIA, IDS Ltd.). All these analytical methods used were validated previously. ${ }^{37}$

The $\mathrm{pH}$ was only analyzed to exclude aberrant values as these might affect the ionized calcium concentration and therefore are not shown separately. Likewise, the creatinine concentration in blood was only used for calculating the fractional urinary excretion (FE), and separate values were not shown.

For urine samples, within $24 \mathrm{hr}$ before/after blood collection, $10 \mathrm{ml}$ of spontaneous midstream urine was collected. Immediately after collection, the urine samples were stored at $-20^{\circ} \mathrm{C}$ until assayed for creatinine (colorimetry/alkaline picrate, Time Rate, $520 \mathrm{~nm}$, Beckman DXC-600 chemistry analyzer, Beckman Coulter, Woerden, 3447 GW, The Netherlands); calcium (indirect ISE/Ca ionophore membrane, Endpoint, Beckman DXC-600 chemistry analyzer, Beckman Coulter); and inorganic phosphorus (phosphormolybdate, Endpoint 2, $340 \mathrm{~nm}$, Beckman DXC600 chemistry analyzer, Beckman Coulter). Preference was given to depict the fractional excretion of various minerals rather than their concentrations in urine.

Based on plasma and urinary values, the FE of calcium and phosphorous were calculated using the following equation: ${ }^{19}$

$$
\mathrm{FE}_{\mathrm{Ca}}=(\mathrm{U} / \mathrm{P})_{\mathrm{Ca}} /(\mathrm{U} / \mathrm{P}) \mathrm{cr} \times 100 \%,
$$

where $\mathrm{U}=$ urinary; $\mathrm{P}=$ plasma; $\mathrm{Ca}=$ calcium, and $\mathrm{cr}=$ creatinine. 
Unfortunately, it was not possible to collect blood and urine samples from all elephants every week during the study period as specified in the footnotes of Tables 3-6.

\section{Ultraviolet-B light measurements}

Ultraviolet-B (UV-B) data based on satellite observations of ozone, cloudiness, presence of aerosols, and surface reflection of UV-B light were provided by the National Institute for Public Health and the Environment (RIVM) in Bilthoven, The Netherlands. In the zoos participating in this study, records were kept of the time the individual elephants spent outside their housing shelter. The values of daily UV-B irradiation (watt per square meter) and period of sunshine as provided by the RIVM and the time spent outdoors, were used to estimate the total amount of UV-B irradiation received by each elephant and compared with plasma concentrations of ionized and total calcium and phosphorous. Due to the small distance between the different zoos (200 miles at maximum), the UV-B data were applied on all the participating zoos.

\section{Wild African elephants}

To obtain an indication of basal blood calcium concentrations in wild African elephants, additional samples were analyzed in South Africa. Serum was used from 20 wild animals stored in the serum bank of the Kruger National Park, South Africa, as no plasma was available from this source. These 20 serum samples were collected in 2005, 2006, and 2007 and equally divided between both sexes. In Hoedspruit, South Africa, two additional venous plasma samples were collected during anesthesia of two healthy female African elephants. In addition, 33 plasma samples collected by a private veterinarian in South Africa were obtained. All these samples were transported frozen to the Onderstepoort Faculty of Veterinary Medicine, University of Pretoria, South Africa, where they were analyzed for total calcium (ACE Calcium-Arsenazo Reagent, 647 nm/692 $\mathrm{nm}$, reagent number AE5-10 ACE Alera, Alfa Klasserman, Siemens Medical Solutions); ionized calcium (silver/silver chloride electrode, Rapid Lab 340, Blood Gas analyzer, Siemens Medical Solutions); and pH (ISE Technology, silver/silver chloride inner conductor, Rapid Lab 340, Blood Gas analyzer, Siemens Medical Solutions). Unfortunately, samples of wild Asian elephants were not available for this study.

\section{Statistical analysis}

To determine whether the data were normally distributed, a Kolmogorov-Smirnov test was applied on all data sets combined with a probability-probability plot. Statistical analysis was performed by one-way analysis of variance using pooled data. When significant effects were detected, the Wilcoxon signed ranks test was performed on the data set of African elephants and the paired $t$-test on the data set of Asian elephants. To compare summer and winter values, the Wilcoxon signed ranks test was used for African elephants $(n=6)$ and the paired $t$-test for Asian elephants $(n$ =13). As only data obtained from Asian elephants were normally distributed, the paired $t$-test was used regarding Asian elephants. The significance of differences between condition (captive versus wild elephants) and gender were assessed by the Mann-Whitney test (two tailed). Correlations were assessed by means of the Pearson's correlation test. All tests were performed using SPSS 18.0 (IBM Corporation, Chicago, Illinois, USA). The significance level $\alpha$ was defined as $P<0.05$ for all tests used.

A likelihood ignorable analysis was used because it uses all available information, without the need neither to delete nor to impute measurements or entire subjects. ${ }^{42}$

\section{RESULTS}

\section{Animals and diets}

The mean regular daily calcium intake of the Asian and African elephants was calculated at $94 \pm$ 31 and $59 \pm 17 \mathrm{mg} / \mathrm{kg}$ BW during summer, respectively, and $75 \pm 20$ and $59 \pm 17 \mathrm{mg} / \mathrm{kg} \mathrm{BW}$ during winter, respectively. The average mean regular daily phosphorus intake of the elephants during summer was $45 \pm 19$ and $45 \pm 16 \mathrm{mg} / \mathrm{kg}$ BW, respectively, and $35 \pm 11$ and $45 \pm 16 \mathrm{mg} / \mathrm{kg}$ BW during winter, respectively (Table 2). Following oral calcium supplementation, the average mean daily calcium intake of the Asian and African elephants during summer was $145 \pm 25$ and $107 \pm$ $8.5 \mathrm{mg} / \mathrm{kg} \mathrm{BW}$, respectively, and $125 \pm 15$ and 107 $\pm 8.5 \mathrm{mg} / \mathrm{kg}$ BW during winter, respectively, associated with an average mean daily phosphorus intake of the elephants during summer of $49 \pm 17$ and $46 \pm 15 \mathrm{mg} / \mathrm{kg} \mathrm{BW}$, respectively, and $35 \pm 9.6$ and $46 \pm 15 \mathrm{mg} / \mathrm{kg}$ BW during winter, respectively.

\section{Clinical biochemistry and endocrinology}

Mean plasma-ionized calcium concentrations were similar in Asian elephants between seasons, 
Table 2. Average daily intake of calcium and phosphorus per elephant in each participating zoo.

\begin{tabular}{|c|c|c|c|c|c|c|}
\hline \multirow[b]{2}{*}{ Zoo } & \multicolumn{2}{|c|}{ Regular diet } & \multicolumn{2}{|c|}{ Calcium-supplemented diet } & \multicolumn{2}{|c|}{ Cholecalciferol-supplemented diet } \\
\hline & $\mathrm{Ca}$ & $\mathrm{P}$ & $\mathrm{Ca}$ & $P$ & $\mathrm{Ca}$ & $\mathbf{P}$ \\
\hline \multicolumn{7}{|l|}{ Summer trial } \\
\hline Safaripark & 71 & 56 & 113 & 57 & 63 & 58 \\
\hline Rhenen Zoo & 35 & 23 & 95 & 25 & 37 & 25 \\
\hline Hannover Zoo & 114 & 57 & 161 & 60 & 109 & 61 \\
\hline Antwerp Zoo & 47 & 16 & 106 & 22 & 53 & 22 \\
\hline \multicolumn{7}{|l|}{ Winter trial } \\
\hline Safaripark & 71 & 56 & 113 & 57 & 63 & 58 \\
\hline Rhenen Zoo & 35 & 23 & 95 & 25 & 37 & 25 \\
\hline Hannover Zoo & 88 & 38 & 135 & 41 & 82 & 42 \\
\hline Antwerp Zoo & 44 & 14 & 103 & 20 & 49 & 20 \\
\hline
\end{tabular}

${ }^{a}$ Both calcium and phosphorus are in milligram per kilogram of body weight.

ranging from $1.21 \pm 0.03$ and $1.25 \pm 0.04 \mathrm{mmol} / \mathrm{L}$ for summer and winter, respectively. The corresponding mean plasma total calcium concentrations were $2.80 \pm 0.32$ and $2.98 \pm 0.19 \mathrm{mmol} / \mathrm{L}$, respectively (Table 4$)$. In addition, mean plasma concentrations of $25(\mathrm{OH})$-cholecalciferol $(37 \pm$ 14 and $40 \pm 11 \mathrm{nmol} / \mathrm{L}$, respectively); $1,25(\mathrm{OH})_{2}-$ cholecalciferol $(8.8 \pm 7.4$ and $11.5 \pm 6.6 \mathrm{pmol} / \mathrm{L}$, respectively); $\mathrm{BAP}(12.7 \pm 5.4$ and $15.1 \pm 9.0 \mu \mathrm{g} /$ $\mathrm{L}$, respectively); and $\mathrm{NT}_{\mathrm{x}}(28.3 \pm 17.6$ and $30.6 \pm$ $15.7 \mathrm{nmol} / \mathrm{L}$ bone collagen equivalent [BCE], respectively) were also similar in Asian elephants between seasons (Table 6).
Unfortunately, initial summer values were not available for African elephants, whereas mean values for ionized calcium, total calcium, and BAP were comparable in winter between both species (Tables 3 and 5). African elephants had higher mean concentrations of $1,25(\mathrm{OH})_{2}$-cholecalciferol $(31.7 \pm 10.8$ and $11.5 \pm 6.6 \mathrm{pmol} / \mathrm{L}$, respectively); and $\mathrm{NT}_{\mathrm{x}}(30.6 \pm 15.7$ and $17.0 \pm$ $10.9 \mathrm{nmol} / \mathrm{L}$ BCE, respectively); and lower mean 25(OH)-cholecalciferol concentrations (22.7 \pm 9.2 and $40 \pm 11 \mathrm{nmol} / \mathrm{L}$, respectively) than Asian elephants in winter.

Table 3. Mean $( \pm$ SD) plasma calcium, phosphorous, and urinary fractional excretion of calcium in African during summer and winter trials. ${ }^{\mathrm{a}}$

\begin{tabular}{|c|c|c|c|c|c|c|}
\hline & $\mathrm{T} 1^{\mathrm{b}}$ & $\mathrm{T} 2^{\mathrm{c}}$ & $\mathrm{T} 3^{\mathrm{d}}$ & $\mathrm{T} 4^{\mathrm{e}}$ & $\mathrm{T} 5^{\mathrm{f}}$ & $\mathrm{T} 6^{\mathrm{g}}$ \\
\hline \multicolumn{7}{|c|}{ Summer ${ }^{\mathrm{h}}$} \\
\hline $\mathrm{ICa}$ & & $1.25(0.06)^{\mathrm{i}}$ & $1.20(0.03)$ & $1.23(0.03)$ & $1.24(0.03)$ & $1.21(0.08)$ \\
\hline $\mathrm{TCa}$ & & $2.84(0.06)$ & $2.79(0.11)$ & $2.83(0.15)$ & $2.97(0.09)$ & $2.88(0.08)$ \\
\hline $\mathbf{P}$ & & $1.31(0.44)$ & $1.21(0.14)$ & $1.56(0.30)$ & $1.55(0.30)$ & $1.32(0.31)$ \\
\hline $\mathrm{FE}_{\mathrm{Ca}}$ & & $9(7)^{\mathrm{i}}$ & $2(1)$ & $5(2)$ & $4(2)$ & $2(2)$ \\
\hline \multicolumn{7}{|l|}{ Winter $^{\mathrm{j}}$} \\
\hline $\mathrm{ICa}$ & $1.22(0.08)$ & $1.17(0.06)^{\mathrm{i}}$ & $1.16(0.02)$ & $1.19(0.08)$ & $1.19(0.07)$ & $1.21(0.04)$ \\
\hline $\mathrm{TCa}$ & $2.88(0.08)$ & $2.80(0.12)$ & $2.89(0.11)$ & $2.90(0.22)$ & $2.82(0.13)$ & $3.05(0.10)^{1}$ \\
\hline $\mathbf{P}$ & $1.30(0.26)$ & $1.34(0.22)$ & $1.31(0.27)$ & $1.34(0.18)$ & $1.41(0.18)$ & $1.44(0.18)$ \\
\hline $\mathrm{FE}_{\mathrm{Ca}}$ & $14(11)$ & $8(7)^{\mathrm{i}}$ & $19(9)$ & $25(5)$ & $13(7)$ & 17 (13) \\
\hline
\end{tabular}

${ }^{\text {a }} \mathrm{ICa}$ is ionized calcium (at $\mathrm{pH}$ 7.4) in $\mathrm{mmol} / \mathrm{L}$; $\mathrm{TCa}$ is total calcium in $\mathrm{mmol} / \mathrm{L} ; \mathrm{P}$ is phosphorus in $\mathrm{mmol} / \mathrm{L}$; $\mathrm{FE}_{\mathrm{Ca}}$ is fractional excretion of calcium in percent.

${ }^{\mathrm{b}} \mathrm{T} 1$ : start of normal diet (28 days before T2).

c T2: start of calcium supplementation.

${ }^{\mathrm{d}}$ T3: start of washout period 1 .

e T4: start of cholecalciferol supplementation.

${ }^{\mathrm{f}}$ T5: start of washout period 2 .

T6: end of washout period (28 days after T5).

${ }^{\text {h }}$ Missing plasma samples included six samples at T1, 1 at T3 during summer. Missing urine samples included six samples at T1, one sample at T2, two samples at T3, 2 samples at T4, one sample at T5, and four samples at T6 during summer $(n=6)$.

${ }^{i}$ Indicates statistical significance between seasons.

${ }^{j}$ Missing plasma samples included two at T3 during winter. Missing urine samples included two samples at T1, three samples at

T2, one sample at T3, three samples at T4, three samples at T5, and one sample at T6 during winter $(n=6)$.

${ }^{k}$ Indicates significant changes as compared with T1, except summer trial (compared with T2). 
Table 4. Mean $( \pm \mathrm{SD})$ plasma calcium, phosphorous, and urinary fractional excretion of calcium in Asian during summer and winter trials. ${ }^{a}$

\begin{tabular}{lcccccc}
\hline & $\mathrm{T}^{\mathrm{b}}$ & $\mathrm{T} 2^{\mathrm{c}}$ & $\mathrm{T}^{\mathrm{d}}$ & $\mathrm{T} 4^{\mathrm{e}}$ & $\mathrm{T}^{\mathrm{r}}$ & $\mathrm{T}^{\mathrm{g}}$ \\
\hline Summer & & & & & & \\
$\mathrm{ICa}$ & $1.21(0.03)$ & $1.29(0.07)^{\mathrm{i}}$ & $1.29(0.04)^{\mathrm{i}}$ & $1.23(0.07)$ & $1.24(0.03)^{\mathrm{i}}$ & $1.25(0.04)^{\mathrm{i}}$ \\
$\mathrm{TCa}$ & $2.80(0.32)$ & $2.89(0.21)$ & $3.10(0.21)^{\mathrm{i}}$ & $3.02(0.20)$ & $2.93(0.18)$ & $2.96(0.16)$ \\
$\mathrm{P}$ & $1.44(0.20)$ & $1.30(0.28)$ & $1.64(0.19)^{\mathrm{i}}$ & $1.58(0.18)$ & $1.48(0.20)$ & $1.56(0.23)^{\mathrm{i}}$ \\
$\mathrm{FE}_{\mathrm{Ca}}$ & $46(60)$ & $66(97)$ & $73(141)$ & $340(34)$ & $51(33)$ & $31(16)$ \\
Winter & & & & & & \\
ICa & $1.25(0.04)$ & $1.25(0.04)$ & $1.25(0.06)$ & $1.25(0.03)$ & $1.29(0.03)^{\mathrm{k}}$ & $1.22(0.06)^{\mathrm{k}}$ \\
$\mathrm{TCa}$ & $2.98(0.19)$ & $2.94(0.14)$ & $3.02(0.22)$ & $2.92(0.12)$ & $3.16(0.20)^{\mathrm{k}}$ & $3.05(0.18)$ \\
$\mathrm{P}$ & $1.41(0.21)$ & $1.52(0.26)$ & $1.47(0.22)$ & $1.66(0.18)^{\mathrm{k}}$ & $1.40(0.15)$ & $1.67(0.17)^{\mathrm{k}}$ \\
$\mathrm{FE}_{\mathrm{Ca}}$ & $42(31)$ & $35(22)$ & $49(24)$ & $39(26)$ & $43(31)$ & $34(24)$ \\
\hline
\end{tabular}

${ }^{\text {a }} \mathrm{ICa}$ is ionized calcium (at $\mathrm{pH}$ 7.4) in $\mathrm{mmol} / \mathrm{L}$; TCa is total calcium in $\mathrm{mmol} / \mathrm{L} ; \mathrm{P}$ is phosphorus in $\mathrm{mmol} / \mathrm{L}$; $\mathrm{FE}_{\mathrm{Ca}}$ is fractional excretion of calcium in percent.

${ }^{\mathrm{b}} \mathrm{T} 1$ : start of normal diet (28 days before $\left.\mathrm{T} 2\right)$

${ }^{\mathrm{c}} \mathrm{T} 2$ : start of calcium supplementation.

d T3: start of washout period 1 .

e T4: start of cholecalciferol supplementation.

${ }^{\mathrm{f}} \mathrm{T} 5$ : start of washout period 2.

${ }^{\mathrm{g}}$ T6: end of washout period (28 days after T5).

${ }^{\mathrm{h}}$ Missing plasma samples included one sample at T4 during summer. Missing urine samples included three samples at T1, one sample at T2, one sample at T3 and three samples at T5 during summer $(n=10)$.

${ }^{\mathrm{i}}$ Indicates significant changes as compared with $\mathrm{T} 1$.

${ }^{j}$ Missing urine samples included one sample at T3 during winter $(n=10)$.

Neither for Asian elephants nor for African elephants a significant correlation could be detected between age and total or ionized plasma calcium concentrations, where total calcium in Asian elephants was $P=0.269$ in the summer and
$P=0.383$ in the winter; ionized calcium in Asian elephants was $P=0.231$ in the summer and $P=$ 0.229 in the winter; total calcium in African elephants was $P=0.082$ in the summer and $P=$ 0.099 in the winter; and ionized calcium in

Table 5. Mean ( \pm SD) plasma concentrations of vitamin D metabolites and bone markers in African elephants during summer and winter trials. ${ }^{\text {a }}$

\begin{tabular}{|c|c|c|c|c|c|c|}
\hline & $\mathrm{T} 1^{\mathrm{b}}$ & $\mathrm{T} 2^{\mathrm{c}}$ & $\mathrm{T} 3^{\mathrm{d}}$ & $\mathrm{T} 4^{\mathrm{e}}$ & $\mathrm{T} 5^{\mathrm{f}}$ & $\mathrm{T} 6^{\mathrm{g}}$ \\
\hline \multicolumn{7}{|l|}{ Summer $^{\mathrm{h}}$} \\
\hline 25(OH) D3 & - & $11.4(4.8)^{\mathrm{i}}$ & $10.8(3.3)$ & $18.5(8.9)$ & $15.7(8.1)$ & $20.5(7.3)$ \\
\hline $1,25(\mathrm{OH})_{2} \mathrm{D} 3$ & - & $17.6(7.4)$ & $19.9(14.3)$ & $17.7(9.0)$ & $19.5(15.6)$ & $23.7(11.0)$ \\
\hline BAP & - & $16.0(18.1)$ & $11.3(4.4)$ & $14.1(11.7)$ & $9.5(1.5)$ & 14.7 (12.9) \\
\hline $\mathrm{NT}_{\mathrm{x}}$ & - & $15.7(10.6)$ & $23.6(11.5)$ & $19.4(9.3)$ & $17.5(9.4)$ & $20.7(10.7)$ \\
\hline \multicolumn{7}{|l|}{ Winter $^{\mathrm{j}}$} \\
\hline $25(\mathrm{OH}) \mathrm{D} 3$ & $22.7(9.2)$ & $15.5(6.3)^{\mathrm{i}}$ & $19.8(10.5)$ & $13.7(8.7)$ & $10.5(2.9)$ & $12.7(5.6)$ \\
\hline $1,25(\mathrm{OH})_{2} \mathrm{D} 3$ & $31.7(10.8)$ & $32.6(11.1)$ & $23.8(4.3)$ & $19.6(10.8)^{\mathrm{k}}$ & $27.8(9.8)$ & $15.8(9.2)^{\mathrm{k}}$ \\
\hline BAP & $15.7(15.1)$ & $15.8(14.5)$ & $19.1(20.3)$ & $15.0(15.2)$ & $16.8(22.0)$ & 17.9 (21.9) \\
\hline $\mathrm{NT}_{\mathrm{x}}$ & $17.0(10.9)$ & $19.6(8.2)$ & $17.6(10.5)$ & $19.9(9.0)$ & $18.9(8.6)$ & $20.2(10.3)$ \\
\hline
\end{tabular}

a $25(\mathrm{OH}) \mathrm{D} 3$ is $25(\mathrm{OH})$-cholecalciferol in $\mathrm{nmol} / \mathrm{L} ; 1,25(\mathrm{OH})_{2} \mathrm{D} 3$ is $1,25(\mathrm{OH})_{2}$-cholecalciferol in pmol/L; BAP is bone alkaline phosphatase in $\mu \mathrm{g} / \mathrm{L} ; \mathrm{NT}_{\mathrm{x}}$ is nitrogen terminal telopeptide of type I collagen in $\mathrm{nM}$ bone collagen equivalent.

${ }^{\mathrm{b}} \mathrm{T} 1$ : start of normal diet (28 days before T2).

${ }^{\mathrm{C}} \mathrm{T} 2$ : start of calcium supplementation.

${ }^{d}$ T3: start of washout period 1.

- T4: start of cholecalciferol supplementation.

${ }^{\mathrm{f}} \mathrm{T} 5$ : start of washout period 2 .

${ }^{\mathrm{g}} \mathrm{T} 6$ : end of washout period (28 days after T5).

${ }^{\mathrm{h}}$ Missing plasma samples included six samples at T1, one sample at T2, one sample (only 1,25(OH)2-cholecalciferol) at T3, one sample (only BAP NTx) at T4 and two samples (only BAP NTx) and at T5 during summer $(n=6)$.

${ }^{\mathrm{i}}$ Indicates statistical significance between seasons.

${ }^{j}$ Missing plasma samples included two samples at T3 during winter $(n=6)$.

${ }^{\mathrm{k}}$ Indicates significant changes as compared with T1, except summer trial (compared with T2). 
Table 6. Mean ( \pm SD) plasma concentrations of vitamin D metabolites and bone markers in Asian elephants during summer and winter trials. ${ }^{\mathrm{a}}$

\begin{tabular}{|c|c|c|c|c|c|c|}
\hline & $\mathrm{T} 1^{\mathrm{b}}$ & $\mathrm{T} 2^{\mathrm{c}}$ & $\mathrm{T} 3^{\mathrm{d}}$ & $\mathrm{T} 4^{\mathrm{e}}$ & $\mathrm{T}^{\mathrm{f}}$ & $\mathrm{T} 6^{\mathrm{g}}$ \\
\hline \multicolumn{7}{|l|}{ Summer $^{\mathrm{h}}$} \\
\hline 25(OH) D3 & 37 (14) & $36(11)$ & $33(10)$ & $33(14)$ & $39(10)$ & $29(12)$ \\
\hline $1,25(\mathrm{OH})_{2} \mathrm{D} 3$ & $8.8(7.4)$ & $9.2(5.5)$ & $8.4(6.2)$ & $7.4(5.1)$ & $9.5(6.2)$ & $4.6(1.2)$ \\
\hline BAP & $12.7(5.4)$ & $14.5(8.9)$ & $16.7(8.4)$ & $16.0(9.0)$ & $16.9(8.5)$ & $16.0(10.2)$ \\
\hline $\mathrm{NT}_{\mathrm{x}}$ & $28.3(17.6)^{\mathrm{i}}$ & 32.7 (22.9) & $29.3(19.8)$ & $29.2(18.0)$ & $33.3(14.7)$ & $24.9(14.7)$ \\
\hline \multicolumn{7}{|l|}{ Winter ${ }^{j}$} \\
\hline 25(OH) D3 & $40(11)$ & $32(11)$ & $27(8)$ & $32(10)$ & 34 (13) & 37 (12) \\
\hline $1,25(\mathrm{OH})_{2} \mathrm{D} 3$ & $11.5(6.6)$ & $5.4(2.2)$ & $6.5(2.6)$ & $11.4(9.8)$ & $10.0(4.7)$ & $7.3(3.4)$ \\
\hline BAP & $15.1(9.0)$ & $16.8(9.0)$ & $13.0(3.8)$ & $15.4(6.9)$ & $16.6(6.4)$ & $16.3(7.1)$ \\
\hline $\mathrm{NT}_{\mathrm{x}}$ & $30.6(15.7)^{\mathrm{i}}$ & $29.9(15.5)$ & $22.7(16.5)$ & $24.9(15.8)$ & $23.5(13.8)$ & $26.9(15.6)$ \\
\hline
\end{tabular}

a $25(\mathrm{OH}) \mathrm{D} 3$ is $25(\mathrm{OH})$-cholecalciferol in $\mathrm{nmol} / \mathrm{L} ; 1,25(\mathrm{OH})_{2} \mathrm{D} 3$ is $1,25(\mathrm{OH})_{2}$-cholecalciferol in pmol/L; BAP is bone alkaline phosphatase in $\mu \mathrm{g} / \mathrm{L} ; \mathrm{NT}_{\mathrm{x}}$ is nitrogen terminal telopeptide of type I collagen in $\mathrm{nM}$ bone collagen equivalent.

${ }^{\mathrm{b}} \mathrm{T} 1$ : start of normal diet (28 days before T2).

${ }^{c}$ T2: start of calcium supplementation.

d T3: start of washout period 1 .

'T4: start of cholecalciferol supplementation.

${ }^{\mathrm{f}} \mathrm{T} 5$ : start of washout period 2.

${ }^{g}$ T6: end of washout period (28 days after T5).

${ }^{\mathrm{h}}$ Missing plasma samples included two samples at T2, two samples (only BAP and $\mathrm{NT}_{\mathrm{x}}$ ) during $\mathrm{T}$, two samples (only $1,25(\mathrm{OH}) 2$-cholecalciferol) at T5, and three at T6 during summer $(n=10)$.

${ }^{i}$ Indicates statistical significance between seasons.

${ }^{\mathrm{j}}$ Missing plasma samples included three samples at T1, two samples at T3, one sample at T5, and one sample at T6 during winter $(n=10)$.

African elephants was $P=0.256$ in the summer and $P=0.127$ in the winter.

The control diet fed to the elephants in the participating zoos was estimated to contain a mean calcium concentration ranging from 35-114 $\mathrm{mg} / \mathrm{kg} \mathrm{BW}$ at the beginning of the summer trial and from $35-88 \mathrm{mg} / \mathrm{kg} \mathrm{BW}$ at the beginning of the winter trial. Following calcium supplementation by using special pellets, the mean estimated calcium concentration fed to the elephants in the participating zoos increased considerably (Table 2).

In the Asian elephants, there was a significant (T3: $P=0.005$ ) increase in mean plasma total calcium concentration by $10.7 \%$ following calcium supplementation during summer (Table 4). During winter, both mean total and ionized plasma calcium concentrations changed significantly by 6.0 and $3.2 \%$, respectively, following cholecalciferol supplementation in Asian elephants (T5: $P=0.009$ and $P<0.001$, respectively). Mean plasma-ionized calcium concentration decreased significantly (T6: $P=0.025$ ) by $2.4 \%$ at the end of the winter trial. Mean plasma inorganic phosphorus concentration increased significantly (T3: $P=0.003$ ) by $13.9 \%$ following calcium supplementation during summer and after the end of the summer trial (T6: $P=0.036$ ) by $8.3 \%$. During winter, mean plasma phosphorus concen- tration increased significantly prior to cholecalciferol supplementation (T4: $P=0.005$ ) by $17.7 \%$ and after the end of the winter trial (T6: $P=0.002$ ) by $18.4 \%$.

In African elephants, significant changes were detected only during winter, which consisted of an increase in mean plasma total calcium concentration at the end of the trial (T6: $P=0.028$ ) by $5.9 \%$ and a decrease in mean plasma $1,25(\mathrm{OH})_{2}$-cholecalciferol concentration prior to cholecalciferol supplementation (T4: $P=0.043$ ) by $30.2 \%$ and at the end of the (winter) trial (T6: $P=0.043$ ) by $50.2 \%$.

Some mean values altered significantly when summer and winter trials were compared. In Asian elephants, mean plasma creatinine (109 \pm $20 \mu \mathrm{mol} / \mathrm{L}$ versus $116 \pm 21 \mu \mathrm{mol} / \mathrm{L} ; P=0.024)$ and $\mathrm{NT}_{\mathrm{x}}$ concentrations $(28.04 \pm 16.47 \mathrm{nM} \mathrm{BCE}$ $(n=48)$ versus $25.5 \pm 14.87 \mathrm{nM} \mathrm{BCE}(n=48) ; P=$ 0.025 ) differed significantly between summer and winter. In African elephants, mean plasma-ionized calcium was $3 \%$ higher $(P=0.007)$ in summer $(1.23 \pm 0.05 \mathrm{mmol} / \mathrm{L})$ compared with winter $(1.19$ $\pm 0.06 \mathrm{mmol} / \mathrm{L})$. In addition, mean plasma 25 hydroxycholecalciferol in African elephants was $0.6 \%$ higher $(P=0.009)$ in summer $(15.7 \pm 7.5$ $\mathrm{nM} / 1)$ than in winter $(15.6 \pm 8.0 \mathrm{nmol} / \mathrm{L})$, whereas fractional excretion of calcium was 3.7 times lower $(P=0.003)$ in summer than in winter 
Table 7. Plasma and serum total and ionized calcium concentrations (mmol/L) in wild African elephants from South Africa in comparison with captive African elephants in West European zoos.

\begin{tabular}{|c|c|c|c|c|c|c|c|c|}
\hline & \multicolumn{6}{|c|}{ Wild African elephants } & & \\
\hline & \multicolumn{2}{|l|}{ Total } & \multicolumn{2}{|l|}{ Male } & \multicolumn{2}{|l|}{ Female } & \multicolumn{2}{|c|}{ Captive African elephants } \\
\hline & Mean \pm SD & $n$ & Mean \pm SD & $n$ & Mean \pm SD & $n$ & Mean \pm SD & $n$ \\
\hline \multicolumn{9}{|c|}{ Total calcium } \\
\hline Plasma & $2.48 \pm 0.18$ & 35 & $2.51 \pm 0.18$ & 22 & $2.37 \pm 1.12$ & 13 & $2.87 \pm 0.13$ & 6 \\
\hline Serum & $2.63 \pm 0.21$ & 20 & $2.65 \pm 0.25$ & 13 & $2.58 \pm 0.14$ & 7 & - & \\
\hline \multicolumn{9}{|c|}{ Ionized calcium } \\
\hline Plasma & $1.03 \pm 0.13$ & 18 & $1.06 \pm 0.12$ & 13 & $0.98 \pm 0.35$ & 5 & $1.20 \pm 0.06$ & 6 \\
\hline Serum & $0.96 \pm 0.21$ & 20 & $1.0 \pm 0.23$ & 13 & $0.92 \pm 0.09$ & 7 & - & \\
\hline
\end{tabular}

a The captive elephants were all female.

$(4.42 \pm 4.01$ versus $16.31 \pm 9.95 \%$ respectively $)$ Remarkably, the fractional excretion of calcium did not change significantly over time during both trials most likely associated with the rather large SD.

\section{UV-B light measurements}

The amount of UV-B radiation is shown in Table 8. However, the amount of UV-B radiation differed significantly between the various periods in summer and winter trial. No significant correlation between various biological measurements and UV-B irradiation were detected.

\section{Wild African elephants}

Serum and plasma data for wild elephants are presented in Table 7. Total plasma calcium concentration was $17.4 \%$ lower $(P<0.001)$ in the studied wild female animals compared with their captive female counterparts, whereas the corresponding value for plasma ionized calcium was $18.3 \%$ lower $(P=0.039)$. Furthermore, plasma ionized calcium were significantly $(P=$ 0.001 ) higher $(8.2 \%)$ in wild male elephants compared with wild females.

\section{DISCUSSION}

Little is known about the calcium status in elephants. The few reports available indicate that elephants resemble the equine species with reference to calcium status ${ }^{4,20,41}$ as elephants absorb calcium almost unlimitedly from the intestines similar to the horse and in contrast to the bovine species. $^{8,32}$ On the other hand, high urinary calcium concentrations have also been reported in captive elephants ${ }^{29}$ similar to the equine species.

For the purpose of the present study, it was hypothesized that oral calcium and cholecalcifer- ol supplementation were effective in normalizing plasma (ionized) calcium concentrations in case of potential hypocalcemia. Asian elephants in this study showed a significant increase in plasma total calcium concentration following calcium (T3) supplementation during summer, thereby suggesting subclinical hypocalcemia during summer as its calcium concentration could be increased. During winter, both mean plasmaionized calcium and plasma total calcium concentrations increased significantly following cholecalciferol supplementation (T5), whereas it decreased 28 days after cessation of cholecalciferol supplementation (T6) in the same animals, suggesting subclinical hypocalcemia during winter as reported previously. ${ }^{20}$ In contrast, subclinical hypocalcemia could be demonstrated neither in summer nor winter in African elephants as based on mean plasma (ionized) calcium concentration monitored during both feeding trials.

Asian elephants, like horses, are less dependent on cholecalciferol to absorb calcium from their gut and probably maintain their calcium plasma level predominantly via renal calcium excretion. ${ }^{13}$ The fact that the small intestine of E. maximus is about twice as long as the small intestine of $L$. africana might also be of importance. ${ }^{33}$ From an evolutionary point of view, this may have been the result of natural selection, making the Asian elephant more of a forest dweller than the African elephant, less dependent on UV-B light by increasing the calcium-absorption surface by means of a longer small intestine, suggesting enhanced paracellular calcium absorption. ${ }^{7}$

One of the functions of cholecalciferol is to increase the absorption of calcium and phosphorus from the intestines. ${ }^{7}$ In this study, the oral cholecalciferol supplementation (T5) to the Asian elephants either during summer or winter resulted in an increase in mean plasma calcium concen- 
Table 8. Amount of UV-B irradiation in cholecalciferol spectrum.

\begin{tabular}{lcccrr}
\hline $\mathrm{UV}-\mathrm{B}\left(\mathrm{W} / \mathrm{m}^{2}\right)$ & $\mathrm{T}^{2}-\mathrm{T} 2^{\mathrm{a}}$ & $\mathrm{T} 2-\mathrm{T}^{\mathrm{b}}$ & $\mathrm{T}^{\mathrm{a}}-\mathrm{T} 4^{\mathrm{c}}$ & $\mathrm{T}^{\mathrm{C}}-\mathrm{T}^{\mathrm{d}}$ & $\mathrm{T}^{\mathrm{T}-\mathrm{T} 6^{\mathrm{e}}}$ \\
\hline Summer & $1.45-8.09$ & $0.42-8.09$ & $0.74-5.42$ & $0.29-5.32$ & $0.15-2.63$ \\
Winter & $0.03-0.36$ & $0.04-0.21$ & $0.04-0.28$ & $0.06-0.40$ & $0.21-1.90$ \\
\hline
\end{tabular}

a T1-T2: 28 days of normal diet.

b T2-T3: 28 days of calcium supplementation.

c T3-T4: washout period of 28 days.

d T4-T5: 28 days of cholecalciferol supplementation.

e T5-T6: washout period of 28 days.

trations. The Asian elephants also showed a significant increase in plasma total calcium concentration following calcium supplementation (T3: $P<0.001$ ) during summer associated with an increase in plasma phosphorus concentration (T3: $P=0.003$ ). The plasma phosphorus concentration might theoretically reflect the net effect of parathyroid hormone (PTH) by increasing the urinary excretion of phosphorus or by decreasing the rate of tubular reabsorption. ${ }^{7}$ On the other hand, the unexpected increase in mean plasma phosphorus concentration in Asian elephants during several periods (T3 and T6 during summer and $\mathrm{T} 4$ and $\mathrm{T} 6$ during winter) might be due to their supposed higher sensitivity to UV-B irradiation and associated production of cholecalciferol.

Subclinical hypocalcemia could not be demonstrated either in winter or summer in African elephants, based on monitoring of mean plasma (ionized) calcium concentrations during the feeding trial. A possible explanation for this speciesspecific difference is that African elephants inhabit savannahs and are exposed to much more intense UV-B irradiation. To protect its body from the negative influences of strong UV-B irradiation, the African elephant's skin might be better adapted to excessive UV irradiation compared with the Asian elephant. As a consequence, African elephants might have a much higher dermal threshold for cholecalciferol conversion from 7-dehydrocholesterol facilitated by UV-B irradiation in contrast to their Asian counterparts, which inhabit forests mostly. Of interest, the Dutch Health Council concluded that humans with a dark skin color have to stay longer in the sun or should take more cholecalciferol orally, in comparison to humans with a light skin color, to produce the same amounts of cholecalciferol. ${ }^{16}$ Under (lower) UV-B irradiation circumstances in Northwest Europe, it might be hypothesized that African elephants rely on intestinal cholecalciferol absorption more heavily especially in winter. Interestingly, a decrease in plasma $1,25(\mathrm{OH})_{2}-$ cholecalciferol concentration even prior to cholecalciferol supplementation was seen in the African elephants at the end of the winter trial. Furthermore, intestinal calcium absorption following oral calcium supplementation might be hampered in African elephants due to relative $25(\mathrm{OH})$-cholecalciferol and/or 1,25( $\mathrm{OH})_{2}$-cholecalciferol deficiencies. Because of the presence of relatively high levels of cholecalciferol, extra calcium administered orally can be absorbed from the gut immediately, and as a consequence Asian elephants will react more strongly on calcium supplementation compared with African elephants. ${ }^{12,16}$

To the authors' knowledge, only one study mentioned serum cholecalciferol concentrations namely in captive African elephants in Florida. ${ }^{24}$ The mean concentration of $25-(\mathrm{OH})$-cholecalciferol in that study was $39.4 \pm 18.7 \mathrm{nmol} / \mathrm{L}$ compared with data for $L$. africana in the range of $15.6 \pm 7.7 \mathrm{nmol} / \mathrm{L}$ and for E. maximus in the range of $35.6 \pm 11.7 \mathrm{nmol} / \mathrm{L}$ from the current study. No significant correlation between either calcium or phosphorus and 25-(OH)-cholecalciferol was observed. A significant seasonal variation or a significant relationship with age could also not be detected. An explanation for a higher 25- $(\mathrm{OH})$-cholecalciferol concentration in the elephants in Florida might be that this region is exposed to more UV-B irradiation than The Netherlands $\left(28^{\circ} \mathrm{N}\right.$ versus $\left.52^{\circ} \mathrm{N}\right)$ due to its geographic location; therefore, the elephants are likely to receive more UV-B light in Florida, thereby synthesizing more endogenous cholecalciferol. Based on a study in San Diego (California), it was concluded that their diet was sufficient and that calcium and phosphorus values were even higher in elephants kept in zoos than in wild elephants. This specific study analyzed the plasma values of wild elephants that were captured and moved to San Diego Zoo. ${ }^{31}$ No evidence of (subclinical) hypocalcemia was detected in these animals. However, San Diego is also closer to the equator with the degree of longitude of San Diego 
being $33^{\circ} \mathrm{N}$ and of Rotterdam $52^{\circ} \mathrm{N}$. At latitudes above $55^{\circ} \mathrm{N}$, the UV-B irradiation is only strong enough from March through September to produce sufficient amounts of cholecalciferol in the skin of humans and sheep. ${ }^{16,28}$ However, it was not mentioned in which period of the year these elephants were moved. Based on monitoring mean plasma (ionized) calcium concentration during both feeding trials, subclinical hypocalcemia could be demonstrated neither in summer nor in winter in African elephants. The African elephants in this study were regarded as normocalcemic but may need some extra cholecalciferol in their diet during winter months. From October through March, the natural UV-B light in Northwest Europe is not sufficient for cholecalciferol production in the skin in sheep. ${ }^{28}$ Whether or not this is also true for African elephants is not known.

The findings in the current study support the opinion that the calcium status of E. maximus is comparable to the calcium status in horses as stated previously. ${ }^{4,20,41}$ The Asian elephants in this study had characteristically high plasma total and ionized calcium concentrations, very similar to horses. ${ }^{3,15,21}$ These values were also much higher than International Species Information System reference values. ${ }^{24}$ Plasma phosphorus and 25$(\mathrm{OH})$-cholecalciferol concentrations were also comparable to horses..$^{3,15}$ No significant changes in plasma total calcium concentrations were detected in horses when fed more or less cholecalciferol, indicating that, in the equine species, cholecalciferol administration (in any form) had no influence on its plasma level. ${ }^{3}$ As shown in the current study this also seems to be the case in African elephants, at least during summer.

No significant changes with reference to overall mean plasma concentrations of calcium (total calcium $P=0.083$; ionized calcium $P=0.375)$, phosphorus $(P=0.475)$, BAP $(P=0.797)$, vitamin D metabolites $(25(\mathrm{OH})-\mathrm{CC} P=0.145 ; 1,25(\mathrm{OH}) 2-$ CC $P=0.921)$ or $\mathrm{FE}$ of calcium $(P=0.385)$ between summer and winter months in Asian elephants were found in this study. $\mathrm{NT}_{\mathrm{x}}$ plasma concentrations were significantly lower during winter in Asian elephants $(P=0.025)$, illustrating the occurrence of calcium absorption from bone. African elephants showed significant changes in overall mean-ionized calcium plasma concentration $(P=0.007), 25-(\mathrm{OH})$-cholecalciferol $(P=$ $0.009)$ plasma concentration, and FE of calcium $(P=0.003)$ between summer and winter, perhaps due to a larger UV-B irradiation dependency. Plasma concentrations of total calcium $(P=$
0.439), phosphorus $(P=0.480), 1,25(\mathrm{OH}) 2-\mathrm{CC}$ $(P=0.278)$ or bone markers (BAP: $P=0.424 ; \mathrm{NT}_{\mathrm{x}}$ : $P=0.232)$ did not differ significantly.

Unexpectedly, total as well as ionized calcium concentrations in plasma in the wild African elephants in this study were significantly lower than in the captive conspecifics. Similar differences for total plasma calcium concentrations were described in a previous report. ${ }^{31}$ Most of these wild animals were sedated before blood collection in contrast to the captive elephants. However, sedation should have minimal effect on the calcium levels in plasma. ${ }^{31}$ Other differences between the two groups were diet, the amount of UV-B irradiation and level of exercise. One might consider that plasma calcium concentrations in these wild animals do not reflect the optimal concentrations, as most of the elephants concerned were living in overpopulated areas, where one might expect a decrease in calcium-rich foliage. There is evidence that wild elephants of both species have clear feeding preference for shrubs and bushes with very high calcium concentrations, thereby illustrating the challenges for these giant terrestrial vertebrates in maintaining calcium homeostasis. ${ }^{43}$

Unfortunately, an appropriate PTH assay was not available during the time this study was performed. PTH is a very important hormone in calcium homeostasis. It is produced and secreted by the parathyroid glands when plasma calcium levels are (too) low in order to restore calcium homeostasis by stimulating bone resorption and increasing renal tubular resorption of calcium and accelerating production of $1,25(\mathrm{OH})_{2}$-cholecalciferol to increase plasma calcium levels. ${ }^{7}$ If an animal suffers from nutritional hypocalcemia, plasma PTH concentrations will increase and will decrease as soon as the restored the amount of calcium in blood. Because this hormone is not influenced by sunlight as much as vitamin D metabolites and given its clear biologic function, it would have been a valid addition to this study.

\section{CONCLUSIONS}

Dietary calcium levels seem to play a superior role in Asian elephants compared with the influence of natural UV-B irradiation. The African elephants in their natural environment may be strongly influenced by natural UV-B irradiation and as a result may be more dependent on 1,25$(\mathrm{OH})$-cholecalciferol. The present study suggests a daily dietary calcium intake of $95 \mathrm{mg} / \mathrm{kg} \mathrm{BW}$ for Asian elephants rather than $45 \mathrm{mg} / \mathrm{kg}$ BW (the latter range as based on a calcium content in the 
DM of $0.3-0.7 \%$ ), depending on the condition of the animal (growing, pregnant, or lactating) with $95 \mathrm{mg} / \mathrm{kg}$ BW being the lower limit of the calculated calcium intake during calcium supplementation of the current trial. It is strongly advised to monitor blood calcium concentrations and, if available, blood PTH levels to adjust the nutritional supplementation for each individual elephant accordingly.

Acknowledgments: The authors are grateful to the support of the zoo keepers, nutritionist Joeke Nijboer, veterinary technicians Aryanna Herscheid and Mark de Boer of Rotterdam Zoo. The elephant-keeping staff members of Rotterdam Zoo, Antwerp Zoo, Hannover Zoo, Safaripark Beekse Bergen, Rhenen Zoo, and Amsterdam Zoo as well as their respective veterinarians. The authors thank the RIVM Bilthoven for providing the UV irradiation datasets. The authors also thank Menarini for supplying the Spotchem for measuring total calcium, creatinine, and inorganic phosphorus concentrations in plasma, Siemens for lending us the Rapid Lab 850 for measuring the ionized calcium, the Erasmus University, Rotterdam, for the measurements of the cholecalciferol concentrations and the bone markers, Blgg for the discounts on the feed analyses, Brink Accountants for the financial support for the transport and analyses of the samples in South Africa, Dr. Peter Buss for help with the samples from the Kruger National Park, and, of course, the Kruger National Park for the samples. The authors are also grateful to Martine van Zij1 Langhout for collecting the samples in Hoedspruit, Douw Grobler for collection the other plasma samples in South Africa, and the Onderstepoort University of Pretoria for the support and the analyses of the samples of the wild African elephants.

\section{LITERATURE CITED}

1. Allen, J. Z., E. R. Jacobson, J. W. Harvey, and W. Boyce. 1985. Hematologic and serum chemical values for young African elephants (Loxodonta africana) with variations for sex and age. J. Zoo Wildl. Med. 16: 98-101.

2. Belterman, R. 2004. Status of the Asian Elephant. EEP EAZA News. 47:11-13.

3. Breidenbach, A., C. Schlumbohm, and J. Harmeyer. 1998. Peculiarities of vitamin D and of the calcium and phosphate homeostatic system in horses. Vet. Res. 29: 173-186.

4. Brown, I. R., and P. T. White. 1977. Serum calcium, magnesium, phosphorus and alkaline phosphatase in the African elephant, Loxodonta africana. Comp. Biochem. Physiol. B. 56: 159-162.
5. Brown, I. R. F., and P. T. White. 1979. Serum electrolytes, lipids, and cortisol in the African elephant, Loxodonta africana. Comp. Biochem. Physiol. A. 62: 899-901.

6. Brown, I. R. F., and P. T. White. 1980. Elephant blood haematology and chemistry. Comp. Biochem. Physiol. 65: 1-12.

7. Capen, C. C., and T. J. Rosol. 2003. The calcium regulating hormones: parathyroid hormone, calcitonin, and cholecalciferol. In: Pineda, M., and M. Dooley (eds.). McDonald's Veterinary Endocrinology and Reproduction, 5th ed. Iowa State Univ. Press, Ames, Iowa. Pp. 71-140.

8. Clauss, M., W. Loehlein, E. Kienzle, and H. Wiesner. 2003. Studies on feed digestibilities in captive Asian elephants (Elephas maximus). J. Anim. Physiol. Anim. Nutr. 87: 160-173.

9. Debbie, J. G., and B. Clausen. 1975. Some hematological values of free-ranging African elephants. J. Wildl. Dis. 11: 79-82.

10. Dierenfeld, E. S. 2006. Nutrition. In: Fowler, M. E., and S. K. Mikota (eds.). Elephant Biology, Medicine, and Surgery, 1st ed., Blackwell Publishing, Ames, Iowa. Pp. 57-65.

11. Dillman, J. S., and W. R. Car. 1970. Observations on arteriosclerosis, serum cholesterol and serum electrolytes in the wild African elephant (Loxodonta africana). J. Comp. Pathol. 80: 81-87.

12. Du Toit, J. G. 2006. Veterinary problems of geographical concern. In: Fowler, M. E., and S. K. Mikota (eds.). Elephant Biology, Medicine, and Surgery, 1st ed. Blackwell Publishing, Ames, Iowa. P. 443.

13. Fowler, M. E., and S. K. Mikota. 2006. Chemistry reference values. In: Fowler, M. E., and S. K. Mikota (eds.). Elephant Biology, Medicine, and Surgery, 1st ed., Blackwell Publishing, Ames, Iowa. Pp. 333-339.

14. Gromadzka-Ostrowska, J., K. Jakubow, B. Zalewska, and Z. Kryzywicki. 1988. Haematological and blood biochemical studies in female domesticated Indian elephants (Elephas maximus L.). Comp. Biochem. Physiol. A. 89: 313-315.

15. Harmeyer, J., and C. Schlumbohm. 2004. Effects of pharmacological doses of vitamin $\mathrm{D}_{3}$ on mineral balance and profiles of plasma vitamin $\mathrm{D}_{3}$ metabolites in horses. J. Steroid Biochem. Mol. Biol. 89-90: 595-600.

16. Health Council of the Netherlands. 2008. Towards an Adequate Intake of Vitamin D. Publication No. 2008/15. Health Council of the Netherlands, The Hague, The Netherlands.

17. Hermes, R., J. Saragusty, W. Schaftenaar, F. Göritz, D. L. Schmitt, and T. B. Hildebrandt. 2008. Obstetrics in elephants. Theriogenology. 70: 131-144.

18. Kilgallon, C., E. Flach, B. Boardman, A. Routh, T. Strike, and B. Jackson. 2008. Analysis of Biochemical markers of bone metabolism in Asian elephants (Elephas maximus). J. Zoo Wildl. Med. 39: 527-536.

19. Koay, E. S. C., and N. Walmsley. 1996. The kidneys and renal disease. In: Koay, E. S. C., and N. Walmsley (eds.). A Primer of Chemical Pathology. 
World Scientific Publishing Co. Pte. Ltd., Singapore, Singapore P. 76.

20. van der Kolk, J. H., J. P. van Leeuwen, A. J. van den Belt, R. H. van Schaik, and W. Schaftenaar. 2008. Subclinical hypocalcaemia in captive Asian elephants (Elephas maximus). Vet. Rec. 162: 475-479.

21. van der Kolk, J. H., R. F. Nachreiner, K. R. Refsal, D. Brouillet, and T. Wensing. 2002. Heparinised blood ionised calcium concentrations in horses with colic or diarrhoea compared to normal subjects. Equine Vet. J. 34: 528-531.

22. Lewis, J. H. 1974. Comparative hematology: studies on elephants, Elephas maximus. Comp. Biochem. Physiol. A. 49: 175-181.

23. Mahasawangkul, S., and T. Angkawanich. 2007. Elephant health status in Thailand-the role of elephant hospitals and mobile elephant clinics. EU-Asia Link Project Symposium. In: Managing the Health and Reproduction of Elephant Populations in Asia. Elephant Hospital, National Elephant Institute, Forest Industry Organization, Lampang, Thailand. Pp. 32-37.

24. MedARKS 5.54.c. 2010. Updated with International Species Information System physiological reference values for elephants on 6 October 2010. International Species Information System, Apple Valley, Minnesota.

25. Miller, M., T. C. Chen, M. F. Holick, S. Mikota, and E. Dierenfeld. 2009. Serum concentrations of calcium, phosphorus, and 25-hydroxyvitamin D in captive African elephants (Loxodonta africana). J. Zoo Wildl. Med. 40: 302-305.

26. Niemuller, C., P. A. Gentry, and R. M. Liptrap. 1990. Longitudinal study of haematological and biochemical constituents in blood of the Asian elephant (Elephas maximus). Comp. Biochem. Physiol. A. 96: 131-134.

27. Nirmalan, G., and S. G. Nair. 1969. Biochemical studies on the blood of Indian elephants (Elephas maximus). Res. Vet. Sci. 10: 176-180.

28. Olds, W. J., A. R. McKinley, M. R. Moore, and M. G. Kimlin. 2008. In vitro model of vitamin $D(3)$ (cholecalciferol) synthesis by UV radiation: doseresponse relationships. J. Photochem. Photobiol. B. 93: 88-93.

29. Rüedi, D. 1995. Elephanten. In: R. Gölthenboth \& H.-G. Klös (eds). Krankheiten de Zoo- und Wildtiere. Blackwell, Berlin, Germany. Pp. 156-189.

30. Sanyathitisaeree, P., N. Yartbantoong, S. Thongthipsiridej, and W. Theeraphan. 2007. Elephant health problems: an accumulative case report from the Kasetsart University Veterinary Teaching HospitalKamphaengsaen. EU-Asia Link Project Symposium. In: Managing the Health and Reproduction of Elephant Populations in Asia. Faculty of Veterinary Medicine, Kasetsart University, Bangkok, Thailand. Pp. 41-48.
31. Schlegel, M. L., D. A. Schmidt, and M. S. Edwards. 2008. Case Study: Changes in blood mineral and vitamin status of free-ranged African bush elephants (Loxodonta africana africana) when translocated to a zoo. Proc. Comp. Nutr. Soc. Liscomb Mills, Nova Scotia, P. 213-228.

32. Schryver, H. F., T. J. Foose, J. Williams, and H. F. Hintz. 1983. Calcium excretion in feces of ungulates. Comp. Biochem. Physiol. A. 74: 375-379.

33. Shoshani, J., R. Alden, K. Andrews, M. J. Baccala, A. Barbish, S. Barry, R. Battiata, and M. P. Bedore. 1982. On the dissection of a female Asian elephant (Elephas maximus) and data from other elephants. Elephant. 2: 3-93.

34. Silva, I. D., and V. Y. Kuruwita. 1993. Hematology, plasma, and serum biochemistry values in freeranging elephants in Sri Lanka. J. Zoo Wildl. Med. 24: 434-439.

35. Silva, I. D., and V. Y. Kuruwita. 1993. Hematology, plasma, and serum biochemistry values in domesticated elephants (Elephas maximus ceylonicus) in Sri Lanka. J. Zoo Wildl. Med. 24: 440-444.

36. Simon, K. J. 1961. Haematological studies on elephants. Ind. Vet. J. 38: 241-245.

37. van Sonsbeek, G. R., J. H. van der Kolk, J. P. T. M. van Leeuwen, and W. Schaftenaar. Preliminary validation of assays to measure parameters of calcium metabolism in captive Asian and African elephants in Western Europe. J. Vet. Diagn. Invest. 23: 504-510.

38. Sreekumar, K. P., and G. Nirmalan. 1989. Mineral status in the blood of Indian elephants (Elephas maximus). Ind. J. Anim. Sci. 59: 1253-1258.

39. Thitaram, C., P. Pongsopawijit, N. Thongtip, T. Angkawanich, S. Chansittivej, and W. Wongkalasin. 2006. Dystocia following prolonged retention of a dead fetus in an Asian elephant (Elephas maximus). Theriogenology 66: 1284-1291.

40. Tuntasuvan, D., N. Phoengpong, W. Jitnupong, and G. Lungka. 2001. Comparison of serum mineral values between captive elephants and free-ranging elephants in Thailand. Kasetsart Univ. Annu. Conf. 2544.

41. Ullrey, D. E., S. D. Crissey, and H. F. Hintz. 1997. Elephants: nutrition and dietary husbandry. In: Nutrition Advisory Group Handbook. American Zoo and Aquarium Association. Pp. 1-20.

42. Verbeke, G., G. Molenberghs. 2000. Linear mixed models for longitudinal data. Springer, New York, New York.

43. Wang, L., L. Lin, Q. He, J. Zhang, L. Zhang. 2007. Analysis of nutrient components of food for Asian elephants in the wild and in captivity. Front. Biol. China 2: 1-5.

Received for publication 26 July 2010 